\title{
The Effect of a Visual Memory Training Program on Chinese Handwriting Performance of Primary School Students with Dyslexia in Hong Kong
}

\author{
Cecilia W. P. Li-Tsang, Agnes S. K. Wong, Linda F. L. Tse, Hebe Y. H. Lam, Viola H. L. Pang, \\ Cathy Y. F. Kwok, Maggie W. S. Lin \\ Department of Rehabilitation Sciences, The Hong Kong Polytechnic University, Hong Kong, China \\ Email: cecilia.li@polyu.edu.hk
}

Received 13 August 2015; accepted 10 November 2015; published 13 November 2015

Copyright @ 2015 by authors and Scientific Research Publishing Inc.

This work is licensed under the Creative Commons Attribution International License (CC BY).

http://creativecommons.org/licenses/by/4.0/

(c) (i) Open Access

\begin{abstract}
This study investigated the effect of a visual memory training program on Chinese handwriting performance among primary school students with dyslexia in Hong Kong. Eight students of Grade 2 to 3 who were diagnosed with dyslexia were recruited. All participants received six sessions of training, which composed of 30-minute computerized game-based visual memory training and 30-minute Chinese character segmentation training. Visual perceptual skills and Chinese handwriting performance were assessed before and after the training, as well as three weeks after training using the Test of Visual Perceptual Skills (3rd edition) (TVPS-3) and the Chinese Handwriting Analysis System (CHAS). In comparing the pre- and post-training results, paired t-tests revealed significant improvements in visual memory skills, as well as handwriting speed, pause time and pen pressure after the training. There was no significant improvement in handwriting accuracy or legibility. The improved visual memory and handwriting performance did not show a significant drop at the follow-up assessments. This study showed promising results on a structured program to improve the Chinese handwriting performance, mainly in speed, of primary school children. The improvements appeared to be well-sustained after the training program. There is a need to further study the long-term effect of the program through a randomized controlled trial study.
\end{abstract}

\section{Keywords}

Visual Memory, Handwriting, Dyslexia, Primary School Students, Chinese 


\section{Introduction}

Handwriting is a crucial task in academic studies and one of the most important means that determines the academic success of students in the Chinese educational system. Students in Hong Kong start their journey of writing since the preschool age. When they are promoted to primary education, over $50 \%$ of their time spent in school is involved with handwriting tasks [1]. Poor handwriting abilities may have adverse effect on students' performance in school tests and public examinations. Apart from academic success, handwriting performance has long-term effects on students' self-esteem [2]-[4].

\subsection{Dyslexia and Its Relation to Handwriting Performance}

In the recently published DSM-V [5], specific learning disorder is the generic term used to describe the disorders (including dyslexia) that are characterized by difficulties in learning which significantly affect academic achievement. The prevalence rate of dyslexia depends on the definition and criteria used, with estimates ranging from 3\% to 10\% [6] [7]. Both Chinese and English speakers with dyslexia have been reported to have difficulties with visual processing and working memory [8]-[11]. Furthermore, visual memory may play a particularly crucial role among Chinese students due to the characteristics and complexity of Chinese characters.

\subsection{Visual Memory Skills in Relation to Reading and Writing Chinese Characters}

Writing systems can basically be divided into logographic (e.g., Chinese and Japanese) and phonographic systems (e.g., English). Previous research found that visual short-term memory (VSTM) plays an important role in reading logographic characters even in skilled adults, and it is most likely due to the increased demands in VSTM and visual attention required for processing complex visual features in logographic symbols [12]. Considering the logographic nature of Chinese characters which involve complex geometric configurations [13]-[15], it is reasonable to predict that visual memory would be particularly important for Hong Kong students to read and write traditional Chinese characters. An appropriate computerized intervention programme might bring enhancement in visual memory abilities among children with dyslexia, which would in turn improve their Chinese handwriting performance. For example, it has been found that time spent on playing video games is related to enhanced visual memory recall performances [16]. In another study, Grade one children with handwriting difficulties showed improvements in handwriting time after participating in the Interactive Computerized Handwriting Training Program (ICHTP)—a training program on visual perception skills [17].

Visual memory (VM) is subdivided into three subsystems: visual sensory memory (VSM), visual short term memory (VSTM) and visual long term memory (VLTM). When a person sees a visual stimulus, visual information is firstly registered in VSM. Higher level memory systems, VSTM and VLTM, draw upon VSM when consolidating the stimulus into more stable forms of memory [18]. The amount of information encoded in VSTM depends on the object discriminability, the amount of allocated attention, and its capacity [19]. However, the capacity of VSTM is limited, which lies in the range of three to four items in children between 5 to 10 years old [20]. There is evidence showing that the larger the capacity of VSTM for certain stimuli, the faster these materials can be learned; in other words, the faster they can be put into VLTM [21].

Change detection, defined by Pashler [22] as the ability to detect changes in briefly-presented visual display items, was applied as one of the principles in our training programme for improving VSTM in the present study. As reported by Angelone, Levin, and Simons [23], an increased ability in change detection tasks can bring about positive outcomes to the encoding and retaining of information in VSTM. Segmentation has also been found to be effective in improving VSTM capacity [21] [24], which reduces the complex visual information into less complex components for more efficient and accurate visual encoding. The acquisition of the visual chunking skills for the recognition of Chinese characters plays a critical role in character processing because young children discriminate written Chinese by stroke-patterns rather than strokes [25] [26], while vast majority of Chinese characters that are commonly used in Hong Kong can be segmented into two to three radicals via different means [27] (Figure 1).

\subsection{Purpose of the Present Study}

Children with dyslexia appear to have handwriting problems such as letter/segment formation, sequencing, orientation, and speed [28]. Prior research has largely focused on the reading problems of students with dyslexia 


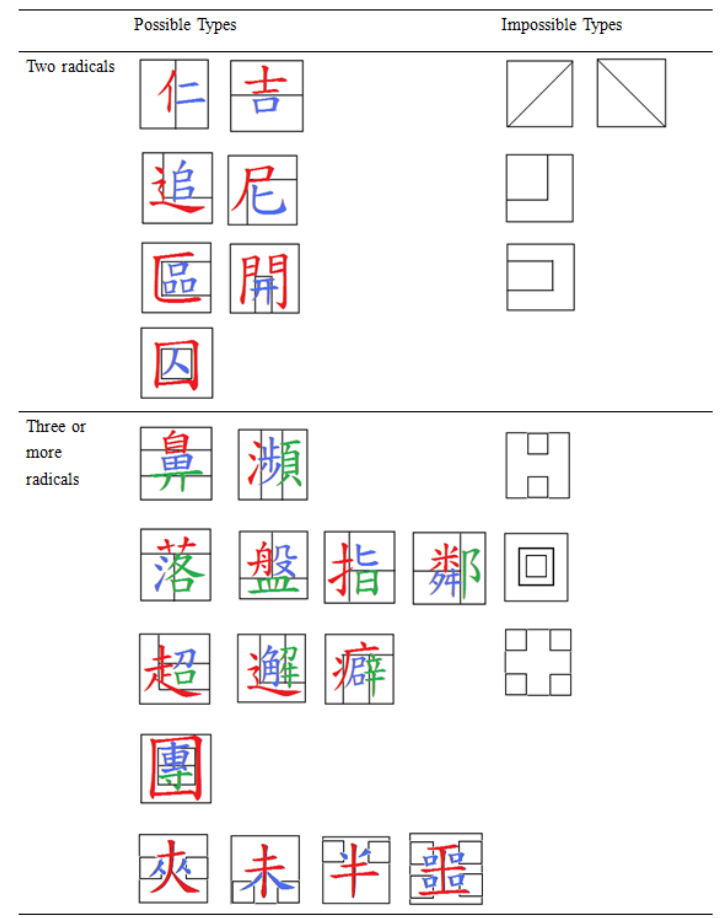

\section{Figure 1. Different types of segmentation technique.}

and that the handwriting problems have usually been neglected [29]. The purpose of this study was to investigate the effect of a specially-designed visual memory training program on the Chinese handwriting ability (in terms of handwriting speed, pen pressure, accuracy and legibility) among primary school students with dyslexia in Hong Kong.

\section{Method}

\subsection{Participants}

Eight primary school children ( 4 boys and 4 girls) from Grade 2 to 3 were recruited by convenience sampling. Their age ranged from 7.21 to 8.97 years ( $M=8.12$ years, $S D=0.59$ years). Seven of them were right-handed. They were diagnosed as having developmental dyslexia by local educational psychologists but no other impairments. Four of them were at Grade 2 and the others were at Grade 3 in local schools in Hong Kong. They used traditional Chinese as the main modality for written expression.

\subsection{Outcome Measures}

\subsubsection{Test of Visual-Perceptual Skills-Third Edition (TVPS-3)}

TVPS-3 was used to assess all of the visual perceptual skills concerned in this study, including VM. It is an individually administered, standardized test that assesses non-motor visual-perceptual skills [30]. The total test of TVPS-3 has been shown to have good test-retest reliability when used on children with learning disabilities (intraclass correlation coefficient (ICC) for the total test standard scores $=0.81$ ). The ICC for the subtests ranges from 0.33 (Sequential Memory) to 0.78 (Form Constancy), and ICC for VM is 0.62, which is adequate for clinical use [31].

\subsubsection{The Chinese Handwriting Analysis System (CHAS)}

CHAS is designed for Chinese students with handwriting difficulties [32]. It is a computerized handwriting evaluation system developed to assess handwriting speed, pen pressure, handwriting accuracy, and character size. The CHAS consists of the Chinese Handwriting Assessment Tool (CHAT) and the Handwriting Analysis 
System (HAS). The CHAT is developed to evaluate the handwriting process of each participant [14] [33] [34], while the data recorded in CHAT can be exported to HAS for further analysis of the handwriting product. The CHAT consists of a digitized writing board (WACOM Intuos 3 digitizer) to be used with an ink pen, which can capture the handwriting data such as pressure exerted on the writing board while a participant is writing on the grid paper. The participant is instructed to sit in front of the computer screen at a distance of $50 \mathrm{~cm}$. A template consists of 90 commonly used Chinese characters at Grade 1 level selected from a list of Chinese Characters recommended for the subject of Chinese Language in primary schools in Hong Kong [34]. During the assessment, characters with size of 26 and font type of Simsun are shown on the computer screen, and displayed in 9 columns of 10 rows. The display sequence of the columns is randomized each time when the system is operated. Each participant is instructed to copy the 90 characters as quickly and accurately as possible on a piece of paper with a $9 \times 10$ grid pasted on the handwriting digitizer (Figure 2), while the characters should be readable and legible. Besides, they are asked to write just like what they used to write in daily life, and to write each character inside the grid accordingly and not to correct their writing if they write a character wrongly.

CHAT provides the following information: 1) total writing time (s), 2) in-air time (s), 3) on-paper time (s), 4) the ratio of pause time to on-paper time, 5) speed (characters/min), 6) standard deviation (SD) of writing time per character (s), 7) pen pressure (Newton), and (8) SD of pen pressure. HAS provides the following information:(1) accuracy rate, 2) total number of characters with stroke errors, 3) total number of characters which exceeded the grid, and 4) SD of the size of each character (mm).

\subsubsection{Parents' Questionnaire}

Feedbacks from parents were collected through questionnaires completed one month after the six sessions of training program. Parents rated their level of agreement and commented on four main areas: 1) arrangement of the training program, 2) participants' perceived motivation towards the training, 3) participants' perceived performance after the training program in (a) handwriting speed, (b) pen pressure, (c) accuracy, (d) legibility, and (e) visual memory ability, and 4) overall comments on the training program.

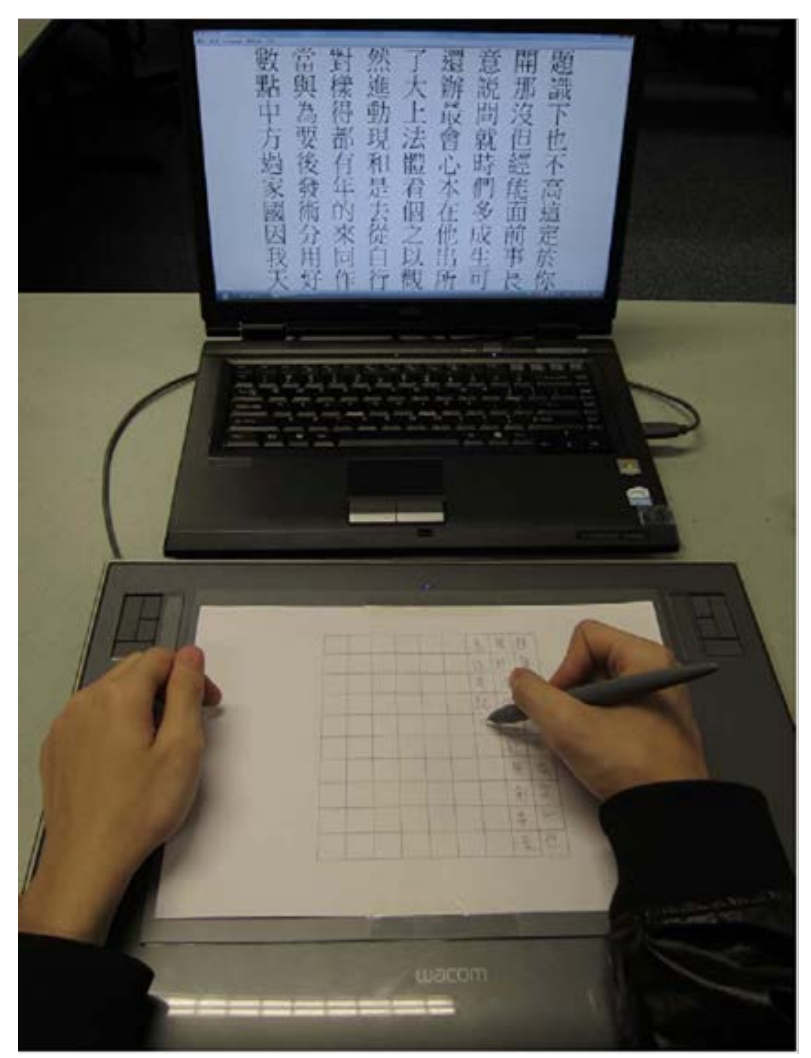

Figure 2. The CHAS system is composed of a laptop computer with the software installed, a digitized writing board (WACOM Intuos 3 digitizer), an ink pen, and a grid paper. 


\subsection{The Training Program}

\subsubsection{The Computerized Game-Based VM Training}

Design of the computerized training considered the format of change detection tasks and aimed to improve participant's memory capacity. In each session, the training contained four different categories of visual stimuli: 1) simple shape, 2) simple cartoon, 3) picture of a real object, and 4) number or Chinese character (Figure 3). A maximum of four visual stimuli were shown in each question of Categories 1 to 3 . The training activities emphasized VM in relation to the size, shape, color, orientation and number of various visual stimuli. For Category 4, each question was presented with one visually complicated Chinese character in terms of number of strokes, radicals and special configuration [8]. All the Chinese characters were of Grade two to three levels extracted from the teaching resources for students of the corresponding level from the Education Bureau of Hong Kong SAR [35].

The training program was designed as a PowerPoint presentation and the visual stimuli were displayed on an electric projector with a screen size of " $43 \times 33$ " at a distance of about four meters away from the participants. For each question, participants first viewed the question number presented at the center of the screen (Figure 4).

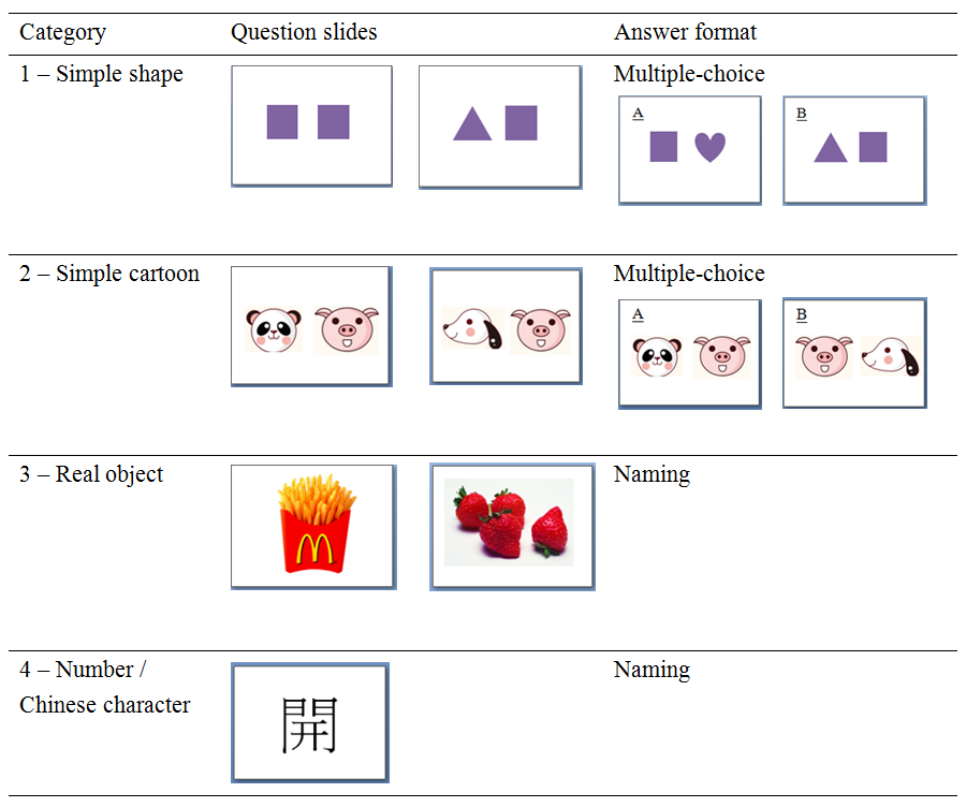

Figure 3. Examples of questions in the computerized VM training program.

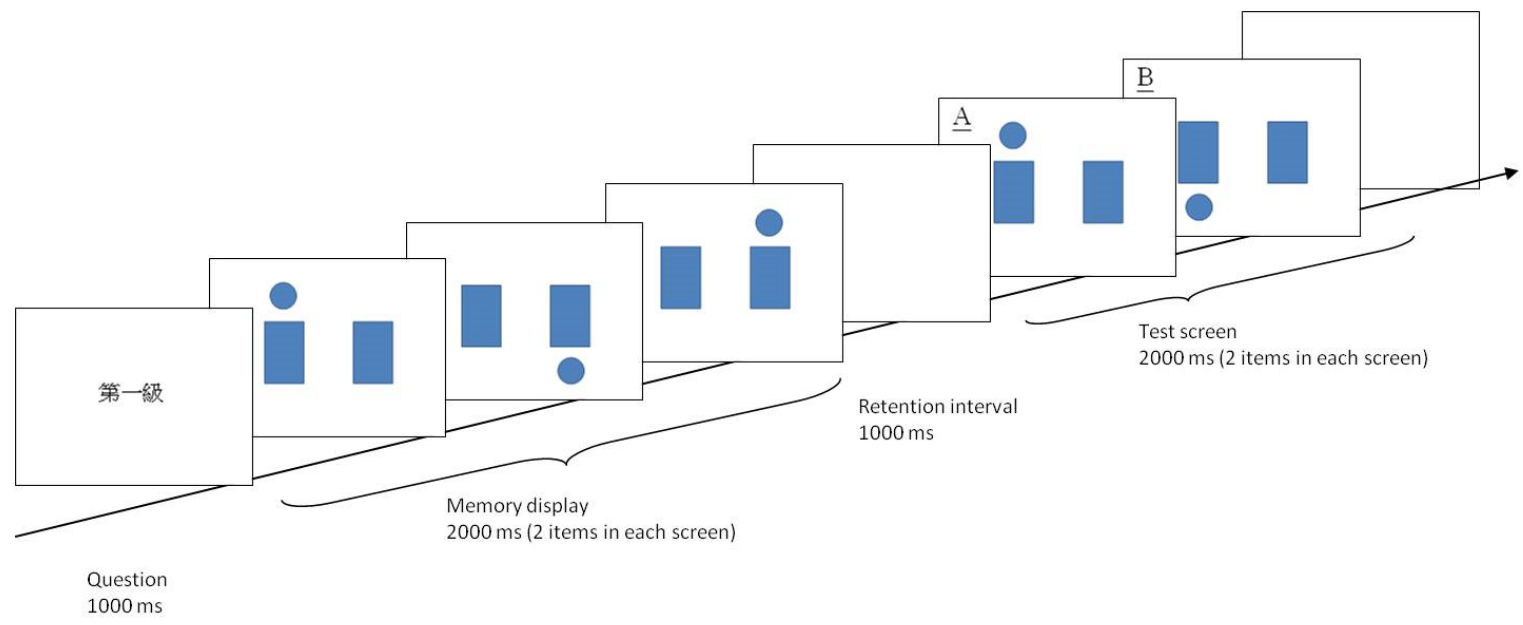

Figure 4. Sample trial used in the computerized VM training program. 
The stimuli were then presented for variable duration based on the categories and number of items in each slide. For Categories 1 to 3, with reference to previous studies on visual working memory [36]-[38], the duration for displaying the visual stimuli was set at $1000 \mathrm{~ms}$ for each item. Category 4 focused on the training related to visual sensory memory, and the display duration of each item was set at $50 \mathrm{~ms}$ [39].

After showing the visual stimuli, a retention slide (blank slide) was shown. For Categories 1 and 2, after a retention interval of $1000 \mathrm{~ms}$, several test displays were shown sequentially and one of them was the target item. Each test screen was displayed for $1000 \mathrm{~ms}$ and was accompanied by an alphabet. After viewing all test screens, a plain white screen was shown and the participants noted the answer (i.e., the alphabet accompanied with the target item) on an answer sheet. For Categories 3 and 4, participants had to write down the names of all the items displayed or the Chinese character shown.

Verbal instructions were given to ensure the participants understand the questions before the session. There was no time limit for answering each question and the next question would be displayed only after all participants in the group had completed the question. No verbal rehearsal or discussion was allowed during the training.

\subsubsection{Chinese Character Segmentation Training}

The Chinese character segmentation training (Figure 5) was given in a worksheet format. Participants had to complete two pages of worksheets in each session. In each page, there were five Chinese characters extracted from a study of the Chinese characters recommended for the subject of Chinese language in primary schools [40]. The characters were decomposed into radicals highlighted with different colors. At the beginning of each session, the trainers first introduced the orientation and writing sequence of the radicals in the Chinese characters on the worksheet. The participants copied each character for five times in grids of size $8 \mathrm{~cm} \times 9 \mathrm{~cm}$ to practice the segmentation technique. The level of difficulty increased with the number of radicals in each character across the training program. There were two radicals in each character in the first two sessions and three radicals in the third to the fifth sessions. In the last session, the number of radicals in each Chinese character varied from two to three. To ensure that the participants utilized the segmentation technique to encode the characters instead

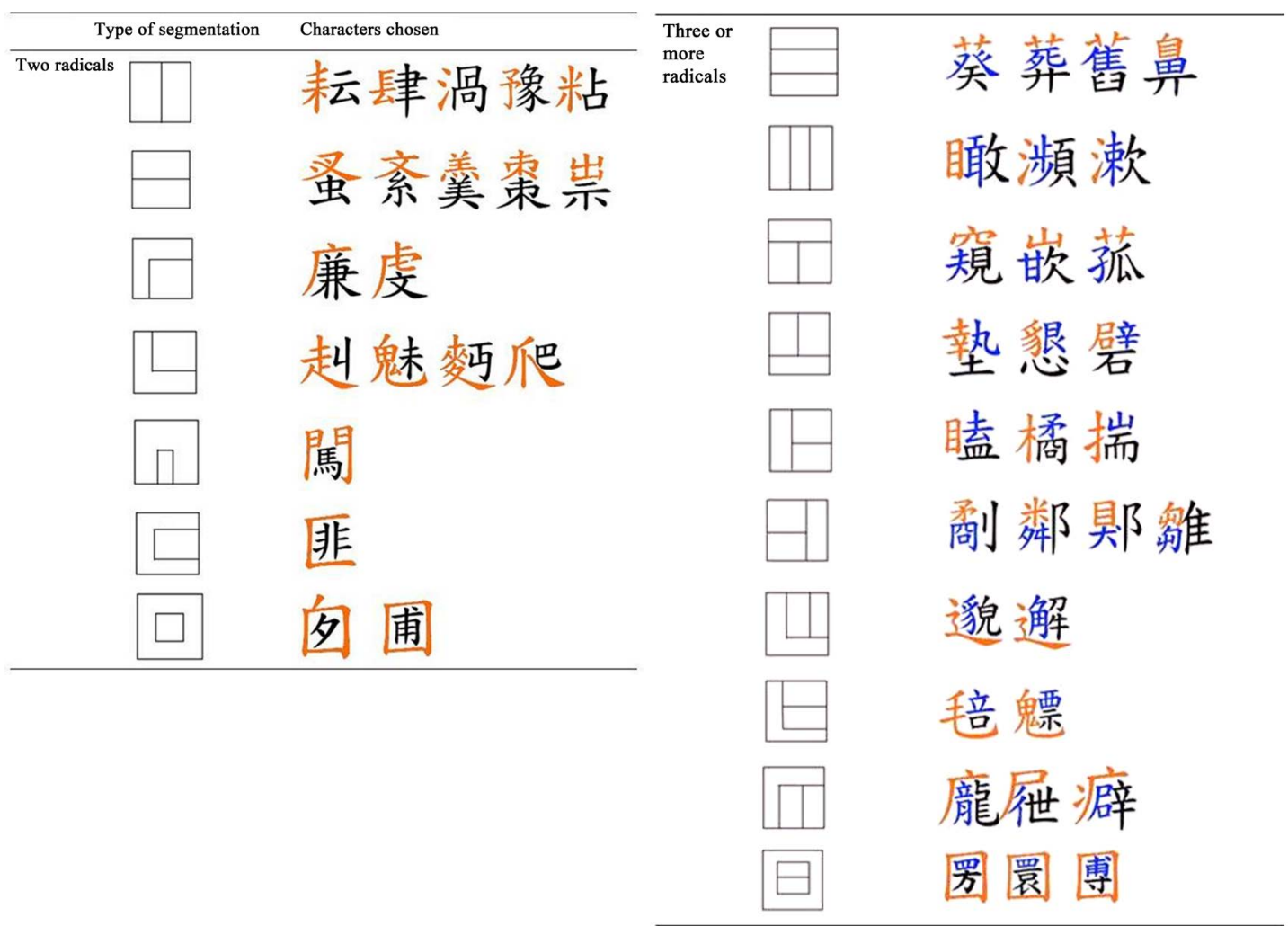

Figure 5. Examples of the Chinese characters segmentation training. 
of writing familiar characters via recall from previous memory, the characters printed on the worksheets were of higher level of difficulty than normal Grade two and three level and appeared unfamiliar to the participants.

\subsubsection{Home Program Worksheet}

A home program in the form of worksheets was provided to strengthen the training effect of segmentation in addition to the training sessions. Participants were required to finish three pages of worksheets using the skills learnt in each session and submit them in the following session.

\subsection{Procedure}

This study was a pretest-posttest design with follow-up. To start with, ethical approval from the Human Subjects Ethics Committee of The Hong Kong Polytechnic University was obtained. Our team contacted non-governmental organizations including the Hong Kong Association for Special Learning Disabilities, Heep Hong Society and the Boys' and Girls' Clubs Association of Hong Kong to recruit students with dyslexia. After screening, parents' consents were collected. The eight recruited participants were randomly allocated into two groups of four.

Pre-training, post-training and follow-up assessments were administered to evaluate visual memory and handwriting performances using TVPS-3 and CHAS respectively. Participants were assessed a week before the first training session and a day after the last training session. The follow-up assessment was conducted three weeks after the post-training assessment. The six training sessions were conducted once a week in six consecutive weeks. Each session lasted for an hour and consisted of two parts, including 30-minute computerized gamebased VM training and 30-minute Chinese character segmentation training. The home program was arranged for the participants under parents' guidance after each session. Parent questionnaires were given four weeks after the training program to evaluate the visual memory and handwriting performances of the participants.

\section{Results}

The eight participants took part in all training sessions and completed the pre-training and post-training assessments. Seven of them finished the follow-up assessment which was conducted three weeks after the intervention. Descriptive statistics (including means and standard deviations) of the TVPS and CHAT items obtained in the three assessment sessions are shown in Table 1 and Table 2. Possible differences in the TVPS scores, handwriting speed, pen pressure, handwriting accuracy and legibility between the three time slots-before, immediately after, and three weeks after the training program, were checked using paired $t$-tests.

\subsection{Comparison of TVPS Outcomes}

Significant differences were found in the overall standard scores $[t(7)=-5.59, p<0.01]$ and the subtest scores of visual discrimination (VD) [t(7) $=-2.49, p<0.05]$, VM $[t(7)=-2.39, p<0.05]$ and figure-ground (FG) [t(7) $=-3.33, p<0.05$ ] before and immediately after the training program (Table 1). No significant difference was demonstrated in the subtests of visual spatial relationship $(p=0.36)$, visual constancy $(p=0.24)$, visual sequential memory $(p=0.86)$, and visual closure $(p=0.21)$ before and after the training. Between the post-training and follow-up assessments, no significant difference was found in the TVPS scores except for spatial relation $[t(6)=$ $-2.56, p<0.05$ ] (Table 2).

\subsection{Handwriting Performance}

Comparing the results before and immediately after the training program (Table 1), significant differences were found in in-air time $[t(7)=2.55, p<0.05]$, pen pressure [t(7) $=2.89, p<0.05]$ and speed (characters per minute) $[t(7)=-2.81, p<0.05]$, while the difference in total copying time was close to significance $(p=0.08)$. No significant difference was found in on-paper time (ground time) $(p=0.27)$, accuracy rate $(p=0.24)$ and number of characters with stroke errors $(p=0.27)$. When comparing the post-training assessment and the follow-up assessment, no significant difference was found in all measured items (Table 2).

\subsection{Parents' Feedback}

Eight questionnaires were collected from the parents of all participants after the six sessions of the training program. The results of the questionnaire are shown in Table 3. 
Table 1. Means, standard deviations and results of paired $t$-tests on TVPS and CHAT measuring items at the pre-training assessment and the post-training assessment.

\begin{tabular}{|c|c|c|c|c|c|}
\hline & \multicolumn{2}{|c|}{ Pre-training assessment $(n=8)$} & \multicolumn{3}{|c|}{ Post-training assessment $(n=8)$} \\
\hline & Mean & SD & Mean & SD & $t(7)$ \\
\hline \multicolumn{6}{|l|}{ TVPS (Scaled Score) } \\
\hline Discrimination & 9.13 & 3.91 & 12.38 & 3.93 & $-2.49^{*}$ \\
\hline Visual memory & 10.00 & 3.16 & 13.25 & 4.30 & $-2.39^{*}$ \\
\hline Spatial relation & 13.37 & 4.37 & 14.50 & 3.07 & -0.99 \\
\hline Form constancy & 9.75 & 4.46 & 11.50 & 4.54 & -1.28 \\
\hline Sequential memory & 9.88 & 2.59 & 10.13 & 3.18 & -0.19 \\
\hline Figure ground & 9.88 & 4.49 & 12.00 & 5.29 & $-3.33^{*}$ \\
\hline Visual closure & 9.75 & 7.09 & 12.12 & 4.73 & -1.38 \\
\hline Overall standard score & 99.50 & 11.63 & 112.38 & 15.15 & $-5.59^{* *}$ \\
\hline \multicolumn{6}{|l|}{ CHAT } \\
\hline Copying time & 676.95 & 241.96 & 573.45 & 207.69 & 2.07 \\
\hline Ground time & 218.18 & 77.18 & 194.96 & 67.37 & 1.19 \\
\hline Air time & 458.77 & 170.04 & 378.49 & 146.14 & $2.55^{*}$ \\
\hline Pen pressure & 1.12 & 0.63 & 0.84 & 0.47 & $2.89^{*}$ \\
\hline Variation of pressure & 0.81 & 0.33 & 0.63 & 0.28 & 2.14 \\
\hline Speed (characters per min) & 9.04 & 3.58 & 10.40 & 3.38 & $-2.81^{*}$ \\
\hline Speed (time per character) & 5.84 & 2.41 & 5.30 & 3.17 & 0.61 \\
\hline Variation of speed (time per character) & 6.40 & 5.38 & 6.81 & 6.48 & -0.15 \\
\hline Exceed grid & 7.38 & 7.07 & 12.00 & 11.07 & -1.73 \\
\hline Character size & 13.35 & 0.63 & 12.54 & 1.42 & 2.23 \\
\hline Variation of character size & 2.10 & 0.43 & 2.07 & 0.44 & 0.252 \\
\hline Accuracy rate & 0.84 & 0.07 & 0.80 & 0.14 & 1.27 \\
\hline Stroke error & 12.25 & 5.28 & 14.00 & 8.50 & -1.19 \\
\hline
\end{tabular}

${ }^{*} p<0.05 ;{ }^{* *} p<0.01$.

Table 2. Means, standard deviations and results of paired $t$-tests on TVPS and CHAT measuring items at the post-training assessment and the 3-week follow-up assessment.

\begin{tabular}{|c|c|c|c|c|c|}
\hline & \multicolumn{2}{|c|}{ Post-training assessment $(n=8)$} & \multicolumn{3}{|c|}{ Follow-up assessment $(n=7)$} \\
\hline & Mean & SD & Mean & SD & $t(6)$ \\
\hline \multicolumn{6}{|l|}{ TVPS (Scaled Score) } \\
\hline Discrimination & 12.38 & 3.93 & 11.00 & 4.32 & 0.31 \\
\hline Visual memory & 13.25 & 4.30 & 15.00 & 3.27 & -1.49 \\
\hline Spatial relation & 14.50 & 3.07 & 16.43 & 3.05 & $-2.56^{*}$ \\
\hline Form constancy & 11.50 & 4.54 & 13.86 & 3.76 & -2.35 \\
\hline Sequential memory & 10.13 & 3.18 & 10.29 & 3.20 & -0.130 \\
\hline Figure ground & 12.00 & 5.29 & 12.57 & 5.22 & -1.04 \\
\hline Visual closure & 12.12 & 4.73 & 11.57 & 4.43 & 0.16 \\
\hline Overall standard score & 112.38 & 15.15 & 114.43 & 15.52 & -1.31 \\
\hline
\end{tabular}




\begin{tabular}{|c|c|c|c|c|c|}
\hline \multicolumn{6}{|l|}{ CHAT } \\
\hline Copying time & 573.45 & 207.69 & 614.31 & 184.37 & -0.74 \\
\hline Ground time & 194.96 & 67.37 & 221.33 & 73.19 & -1.41 \\
\hline Air time & 378.49 & 146.14 & 392.97 & 117.13 & -0.43 \\
\hline Pen pressure & 0.84 & 0.47 & 1.00 & 0.30 & -0.88 \\
\hline Variation of pressure & 0.63 & 0.28 & 0.74 & 0.20 & -1.04 \\
\hline Speed (characters per min) & 10.40 & 3.38 & 9.63 & 3.51 & 0.84 \\
\hline Speed (time per character) & 5.30 & 3.17 & 7.07 & 4.11 & -0.98 \\
\hline $\begin{array}{l}\text { Variation of speed (time per } \\
\text { character) }\end{array}$ & 6.81 & 6.48 & 12.53 & 12.89 & -0.96 \\
\hline Exceed grid & 12.00 & 11.07 & 10.86 & 9.92 & 1.19 \\
\hline Character size & 12.54 & 1.42 & 2.69 & 1.70 & -0.14 \\
\hline Variation of character size & 2.07 & 0.44 & 3.08 & 2.19 & -1.23 \\
\hline Accuracy rate & 0.80 & 0.14 & 0.79 & 0.83 & 0.14 \\
\hline Stroke error & 14.00 & 8.50 & 15.14 & 5.34 & -0.48 \\
\hline
\end{tabular}

${ }^{*} p<0.05$.

Table 3. Results of the parents' questionnaire $(n=8)$.

\begin{tabular}{|c|c|c|c|c|c|}
\hline & Totally agree & Agree & Neutral & Disagree & Totally disagree \\
\hline \multicolumn{6}{|l|}{ Arrangement } \\
\hline Appropriate time & $37.5 \%$ & $50 \%$ & $12.5 \%$ & $0 \%$ & $0 \%$ \\
\hline Appropriate venue & $75 \%$ & $12.5 \%$ & $12.5 \%$ & $0 \%$ & $0 \%$ \\
\hline \multicolumn{6}{|l|}{ Parent's understanding } \\
\hline Understood child's handwriting problem & $0 \%$ & $62.5 \%$ & $37.5 \%$ & $0 \%$ & $0 \%$ \\
\hline Understood method of improving handwriting abilities & $12.5 \%$ & $50 \%$ & $25 \%$ & $0 \%$ & $0 \%$ \\
\hline \multicolumn{6}{|l|}{ Effectiveness of the training program } \\
\hline Child's handwriting accuracy improved & $0 \%$ & $100 \%$ & $0 \%$ & $0 \%$ & $0 \%$ \\
\hline Child's handwriting legibility improved & $12.5 \%$ & $62.5 \%$ & $25 \%$ & $0 \%$ & $0 \%$ \\
\hline Child's writing speed improved & $0 \%$ & $75 \%$ & $12.5 \%$ & $12.5 \%$ & $0 \%$ \\
\hline Child's pen pressure improved & $12.5 \%$ & $62.5 \%$ & $25 \%$ & $0 \%$ & $0 \%$ \\
\hline Child's visual memory improved & $12.5 \%$ & $87.5 \%$ & $0 \%$ & $0 \%$ & $0 \%$ \\
\hline \multicolumn{6}{|l|}{ Engagement } \\
\hline Child was motivated & $62.5 \%$ & $37.5 \%$ & $0 \%$ & $0 \%$ & $0 \%$ \\
\hline \multicolumn{6}{|l|}{ Overall } \\
\hline Satisfied towards the program & $37.5 \%$ & $62.5 \%$ & $0 \%$ & $0 \%$ & $0 \%$ \\
\hline
\end{tabular}

\section{Discussion}

\subsection{Basic Visual Perceptual Skills and Handwriting}

\subsubsection{VM and Overall VP Performance}

Participants showed significant improvements in VM after the 6-week training program. This is consistent with previous studies on VM suggesting that children's VM could be increased to a larger capacity for sustaining individual features in the integration of object percepts (e.g., [24]). A review has also suggested that changedetection is an effective training method for VM [18]. The results shown in the present study advocates that computerized VM training together with training on segmentation techniques is effective in advancing visual memory skills in children. Previous studies have shown that visual perceptual skills are often used in combination 
in the real world; it is therefore expectable that the overall performance of visual perception could also be enhanced once the visual memory skills are improved through training.

\subsubsection{Visual Discrimination and Figure Ground Performance}

The other two subtests of visual perception skills, VD and FG, which were secondary outcome measures, should be examined carefully. The results showed that the improving effect of VM training was generalized to two non-trained domains, VD and FG. Interestingly, neither the computerized training nor the segmentation skill training required VD or FG skills. It therefore suggests that the improvement of VM have effects on the non-trained visual perceptual skills of VD and FG. A previous study on short term memory showed that an increased VM capacity could affect the outcomes of VD task [41]. The improvement in FG is consistent with the study by O'Herron and von der Heydt [42], who suggested that FG organization is related to the process of object identification and STM is essential in continuous perception which is one of the key components in FG skills.

\subsection{Chinese Handwriting Performance}

There was a reduction in the total in-air time and pen pressure, and an increase in handwriting speed, when comparing the pre- with the post-training assessment. In-air time, the pauses in the flows of writing, has been suggested to be the time taken for the registration of character segments during writing [43]. Taking consideration of the significant increase in memory subtest scores of the TVPS together with the significant changes in the CHAS outcomes, our results demonstrated that children could register segments of characters faster with improved visual memory skills after the training, and hence, shortened the pause time during writing. It is suggested that children could, in turn, be able to produce more characters in a given period of time, thus increasing the handwriting speed. This is consistent with the findings of Tseng and Chow [1] that memory subtest scores of the TVPS were positively associated with the speed of handwriting Chinese characters for children in Grades two and six. No significant drop in performance in the outcome measures of CHAS within three weeks after the training illustrated that the improvement in handwriting speed, in-air time and pen pressure could be wellsustained for at least three weeks.

However, there was no significant change across the training for the number of characters which exceeded grid, stroke errors and overall accuracy rate. This indicated that the improvement in visual memory skills alone might not cause any effect on the Chinese handwriting accuracy and legibility. Handwriting performance was affected by a constellation of skills, such as motor, visual-motor integration, cognitive and visual-perceptual processing [44]-[51]. Moreover, handwriting accuracy is highly related to the visual-motor integration skills as reflected by its high correlation with the scores of the Beery-Buktenica Developmental Test of Visual-Motor Integration-5th Edition [52]. Training on VM skills alone for a relatively short duration might not be sufficient to produce improvement in handwriting legibility and accuracy.

\subsection{Qualitative Outcome-Parents' Feedback and In-Session Observation}

Parents' feedback was positive towards the VM training program. All the parents agreed that their children had improvement in handwriting performance in terms of accuracy after the training program, and $75 \%$ agreed that their children wrote faster, more neatly and performed with reduced pen pressure in writing tasks. Concerning the effects of the training program on VM, all the parents agreed that children had improved visual memory skills. All parents agreed (among which 62.5\% strongly agreed) that children had high motivation towards the engagement of this training program. Most parents also reported their children were excited and eager to participate in the program. Most of the participants commented the computerized training program was interesting and attractive. During the training, they were able to answer all the questions actively, showed great effort to attempt difficult questions and eagerness to improve their own performance. Gradual improvement on the computerized training in terms of number of correct answers and handwriting performance in terms of handwriting speed and pen pressure was observed in most of the participants.

\subsection{Implications}

The findings of this study have a number of implications for future practice. In Hong Kong, repetitive copying and dictation are the key strategies used by primary school teachers in order to enhance students' handwriting performance [14]. The present study has shown that the application of segmentation techniques can have positive 
impacts on handwriting. Therefore, it is suggested that this technique should be taken into consideration by primary school teachers as a guiding method in copying tasks for students who are identified with visual memory problems and suffering from handwriting difficulties. By doing this, students may be able to achieve higher competence in handwriting with less monotonous copying in relatively shorter time. Our results provided new insights to therapists that computerized game-based VM training can be adopted as a training tool to address the underlying issues of VM problems and hence facilitate the handwriting performance of primary school students.

\subsection{Limitations of the Present Study}

Some limitations and shortcomings of the present study are noted. There were a limited number of training sessions and restricted length of retention period before the follow-up assessment. Furthermore, the cognitive abilities which might have influences on the development of handwriting skills (including attention, reasoning skills, learning ability and motor skills) [53] were not assessed. Future studies should assess the cognitive abilities and motor skills which might affect the handwriting performance. Moreover, the current study has relatively small sample size and lacks a control group. A larger sample size should be recruited and a control group should be arranged in future studies to address reliability and validity issues. As we found pen pressure improvement in this training program, studies on pen pressure in relation to handwriting speed and VM skills are also recommended.

\section{Conclusion}

This study investigated the effect of a specially-designed computerized VM training program on the Chinese handwriting performance of primary school children with dyslexia in Hong Kong. The VM training program showed a positive effect: a significant improvement was found in visual memory skills, as well as in handwriting speed (characters per minute), in-air time and pen pressure, and the effect sustained for at least three weeks. Participants enjoyed and actively took part in the interactive program. It is hoped that a controlled trial with a larger scale can be conducted in further investigations on the program effectiveness, so that new treatment measures in relation to VM of children with dyslexia can be developed. On the other hand, segmentation techniques should be introduced to primary school teachers to provide an alternative option for teaching Chinese characters to children.

\section{References}

[1] Tseng, M.H. and Chow, S.M.K. (2000) Perceptual-Motor Function of School-Age Children with Slow Handwriting Speed. American Journal of Occupational Therapy, 54, 83-88. http://dx.doi.org/10.5014/ajot.54.1.83

[2] Feder, K.P. and Majnemer, A. (2007) Handwriting Development, Competency and Intervention. Developmental Medicine and Child Neurology, 49, 312-317. http://dx.doi.org/10.1111/j.1469-8749.2007.00312.x

[3] Ingesson, S.G. (2007) Growing Up with Dyslexia: Interviews with Teenagers and Young Adults. School Psychology International, 28, 574-591. http://dx.doi.org/10.1177/0143034307085659

[4] Stampoltzis, A. and Polychronopoulou, S. (2009) Greek University Students with Dyslexia: An Interview Study. European Journal of Special Needs Education, 24, 307-321. http://dx.doi.org/10.1080/08856250903020195

[5] American Psychiatric Association (2013) Diagnostic and Statistical Manual of Mental Disorders. 5th Edition, (DSM-5). American Psychiatric Association, Washington DC.

[6] Ashraf, M. and Majeed, S. (2011) Prevalence of Dyslexia in Secondary School Students in Lahore. Pakistan Journal of Psychological Research, 26, 73-85.

[7] Chan, D.W., Ho, C.S.H., Tsang, S.M., Lee, S.H. and Chung, K.K.H. (2007) Prevalence, Gender Ratio and Gender Differences in Reading-Related Cognitive Abilities Among Chinese Children with Dyslexia in Hong Kong. Educational Studies, 33, 249-265. http://dx.doi.org/10.1080/03055690601068535

[8] Ho, C.S.H., Chan, D.W.O., Lee, S.H., Tsang, S.M. and Luan, V.H. (2004) Cognitive Profiling and Preliminary Subtyping in Chinese Developmental Dyslexia. Cognition, 91, 43-75. http://dx.doi.org/10.1016/S0010-0277(03)00163-X

[9] Huang, H.S. and Hanley, J.R. (1995) Phonological Awareness and Visual Skills in Learning to Read Chinese and English. Cognition, 54, 73-98. http://dx.doi.org/10.1016/0010-0277(94)00641-W

[10] Siok, W.T. and Fletcher, P. (2001) The Role of Phonological Awareness and Visual-Orthographic Skills in Chinese Reading Acquisition. Developmental Psychology, 37, 886-899. http://dx.doi.org/10.1037/0012-1649.37.6.886 
[11] Wilmer, J.B., Richardson, A.J., Chen, Y. and Stein, J.F. (2004) Two Visual Motion Processing Deficits in Developmental Dyslexia Associated with Different Reading Skills Deficits. Journal of Cognitive Neuroscience, 16, 528-540. http://dx.doi.org/10.1162/089892904323057272

[12] Koyama, M.S., Stein, J.F., Stoodley, C.J. and Hansen, P.C. (2011) Functional MRI Evidence for the Importance of Visual Short-Term Memory in Logographic Reading. European Journal of Neuroscience, 33, 539-548. http://dx.doi.org/10.1111/j.1460-9568.2010.07534.x

[13] Chow, S.M.K., Choy, S.W. and Mui, S.K. (2003) Assessing Handwriting Speed of Children Biliterate in English and Chinese. Perceptual and Motor Skills, 96, 685-694. http://dx.doi.org/10.2466/pms.2003.96.2.685

[14] Lam, S.S.T., Au, R.K.C., Leung, H.W.H. and Li-Tsang, C.W.P. (2011) Chinese Handwriting Performance of Primary School Children with Dyslexia. Research in Developmental Disabilities, 32, 1745-1756. http://dx.doi.org/10.1016/j.ridd.2011.03.001

[15] Tan, L.H., Feng, C.M., Fox, P.T. and Gao, J.H. (2001) An fMRI Study with Written Chinese. NeuroReport, 12 , 83-88.

[16] Ferguson, C.J., Cruz, A.M. and Rueda, S.M. (2008) Gender, Video Game Playing Habits and Visual Memory Tasks. Sex Roles, 58, 279-286. http://dx.doi.org/10.1007/s11199-007-9332-z

[17] Poon, K.W., Li-Tsang, C.W.P., Weiss, T.P.L. and Rosenblum, S. (2010) The Effect of a Computerized Visual Perception and Visual-motor Integration Training Program on Improving Chinese Handwriting of Children with Handwriting Difficulties. Research in Developmental Disabilities, 31, 1552-1560. http://dx.doi.org/10.1016/j.ridd.2010.06.001

[18] Luck, S.J. and Hollingworth, A. (2008) Visual Memory. Oxford University Press, New York.

[19] Fougnie, D. (2008) The Relationship between Attention and Working Memory. In: Johansen, N.B., Ed., New Research on Short-Term Memory, Nova Science Publishers, Hauppage, 1-45.

[20] Riggs, K.J., McTaggart, J., Simpson, A. and Freeman, R.P. (2006) Changes in the Capacity of Visual Working Memory in 5- to 10-Year-Olds. Journal of Experimental Child Psychology, 95, 18-26. http://dx.doi.org/10.1016/j.jecp.2006.03.009

[21] Hu, W., Lee, H.L., Zhang, Q., Liu, T., Geng, L.B., Seghier, M.L., Shakeshaft, C., Twomey, T., Green, D.W., Yang, Y.M. and Price, C.J. (2010) Developmental Dyslexia in Chinese and English Populations: Dissociating the Effect of Dyslexia from Language Differences. Brain, 133, 1694-1706. http://dx.doi.org/10.1093/brain/awq106

[22] Pashler, H. (1988) Familiarity and Visual Change Detection. Perception and Psychophysics, 44, 369-378. http://dx.doi.org/10.3758/BF03210419

[23] Angelone, B.L., Levin, D.T. and Simons, D.J. (2003) The Relationship between Change Detection and Recognition of Centrally Attended Objects in Motion Pictures. Perception, 32, 947-962. http://dx.doi.org/10.1068/p5079

[24] Luck, S.J. and Vogel, E.K. (1997) The Capacity of Visual Working Memory for Features and Conjunctions. Nature, 390, 279-281. http://dx.doi.org/10.1038/36846

[25] Chen, Y.P., Allport, D.A. and Marshall, J.C. (1996) What Are the Functional Orthographic Units in Chinese Word Recognition: The Stroke or the Stroke Pattern? Quarterly Journal of Experimental Psychology: Section A, 49, 10241043. http://dx.doi.org/10.1080/713755668

[26] Pak, A.K.H., Cheng-Lai, A., Tso, I.F., Shu, H., Li, W. and Anderson, R.C. (2005) Visual Chunking Skills of Hong Kong Children. Reading and Writing, 18, 437-454. http://dx.doi.org/10.1007/s11145-005-6575-3

[27] Chen, H., Chang, L., Choiu, Y., Sung, Y. and Chang, K. (2011) Chinese Orthography Database and Its Application in Teaching Chinese Characters. Bulletin of Educational Psychology, 43, 269-290.

[28] Rosenblum, S. and Livneh-Zirinski, M. (2008) Handwriting Process and Product Characteristics of Children Diagnosed with Developmental Coordination Disorder. Human Movement Science, 27, 200-214. http://dx.doi.org/10.1016/j.humov.2008.02.011

[29] Berninger, V.W., Nielsen, K.H., Abbott, R.D., Wijsman, E. and Raskind, W. (2008) Writing Problems in Developmental Dyslexia: Under-Recognized and Under-Treated. Journal of School Psychology, 46, 1-21. http://dx.doi.org/10.1016/j.jsp.2006.11.008

[30] Martin, N.A. (2006) Manual of the Test of Visual Perceptual Skills (TVPS-3). 3rd Edition, American Therapy Publications, CA.

[31] Mcfall, S.A, Deitz, J.C. and Crowe, T.K. (1993) Test-Retest Reliability of the Test of Visual Perceptual Skills with Children with Learning Disabilities. American Journal of Occupational Therapy, 47, 819-824. http://dx.doi.org/10.5014/ajot.47.9.819

[32] Li-Tsang, C.W.P., Wong, A.S.K., Leung, H.W.H., Cheng, J.S., Chiu, B.H.W., Tse, L.F.L. and Chung, R.C.K. (2013) Validation of the Chinese Handwriting Analysis System (CHAS) for Primary School Students in Hong Kong. Research in Developmental Disabilities, 34, 2872-2883. http://dx.doi.org/10.1016/j.ridd.2013.05.048 
[33] Cheng, S.J. (2010) Developmental and Validation of a Chinese Handwriting Assessment Tool (CHAT) for Primary School Students. M.Sc. Dissertation, The Hong KongPolytechnic University, Hong Kong.

[34] Li-Tsang, C.W.P., Au, R.K.C., Chan, M.H.Y., Chan, L.W.L., Lau, G.M.T., Lo, T.K. and Leung, H.W.H. (2011) Handwriting Characteristics among Secondary Students with and without Physical Disabilities: A Study with a Computerized Tool. Research in Developmental Disabilities, 32, 207-216. http://dx.doi.org/10.1016/j.ridd.2010.09.015

[35] Education Bureau of HKSAR (2008) Chinese Language Curriculum and Assessment Guide for Primary School Students. Chinese Language Education Section, Curriculum Development Institute, Education Bureau of HKSAR, Hong Kong.

[36] Gao, Z., Yin, J., Xu, H., Shui, R. and Shen, M. (2011) Tracking Object Number or Information Load in Visual Working Memory: Revisiting the Cognitive Implication of Contralateral Delay Activity. Biological Psychology, 87, $296-302$. http://dx.doi.org/10.1016/j.biopsycho.2011.03.013

[37] Olivers, C.N. and Eimer, M. (2011) On the Difference between Working Memory and Attentional Set. Neuropsychologia, 49, 1553-1558. http://dx.doi.org/10.1016/j.neuropsychologia.2010.11.033

[38] Zimmer, H.D., Popp, C., Reith, W. and Krick, C. (2012) Gains of Item-Specific Training in Visual Working Memory and Their Neural Correlates. Brain Research, 1466, 44-55. http://dx.doi.org/10.1016/j.brainres.2012.05.019

[39] Shapiro, K.L. and Miller, C.E. (2011) The Role of Biased Competition in Visual Short-term Memory. Neuropsychologia, 49, 1506-1517. http://dx.doi.org/10.1016/j.neuropsychologia.2011.02.017

[40] Poon, W.Y. and Hong, P.M. (2003) A Study of the Chinese Characters Recommended for the Subject of Chinese Language in Primary Schools. Hong Kong Baptist University Language Centre, Hong Kong.

[41] Goodale, M.A. and Milner, A.D. (1992) Separate Visual Pathways for Perception and Action. Trends in Neurosciences, 15, 20-25. http://dx.doi.org/10.1016/0166-2236(92)90344-8

[42] O’Herron, P. and Von der Heydt, R. (2009) Short-Term Memory for Figure-Ground Organization in the Visual Cortex. Neuron, 61, 801-809. http://dx.doi.org/10.1016/j.neuron.2009.01.014

[43] Benbow, M. (1995) Principles and Practices of Teaching Handwriting. In: Henderson, A. and Pehoski, C., Eds., Hand Function in the Child, Mosby, St. Louis, 255-281.

[44] Alston, J. and Taylor, J. (1987) Handwriting: Theory, Research, and Practice. Croom Helm, New York.

[45] Amundson, S.J. (2001) Prewriting and Handwriting. In: Case-Smith, C., Ed., Occupational Therapy for Children, Mosby, St. Louis, 545-570.

[46] Bonney, M.A. (1992) Understanding and Assessing Handwriting Difficulty: Perspectives from the Literature. Australian Occupational Therapy Journal, 39, 7-15. http://dx.doi.org/10.1111/j.1440-1630.1992.tb01751.x

[47] Carlson, K. and Cunningham, J. (1990) Effect of Pencil Diameter on the Graphomotor Skill of Preschoolers. Early Childhood Research Quarterly, 5, 279-293. http://dx.doi.org/10.1016/0885-2006(90)90049-7

[48] Cornhill, H. and Case-Smith, J. (1996) Factors That Relate to Good and Poor Handwriting. American Journal of Occupational Therapy, 50, 732-739. http://dx.doi.org/10.5014/ajot.50.9.732

[49] Johnson, D.J. and Carlisle, J.F. (1996) A Study of Handwriting in Written Stories of Normal and Learning Disabled Children. Reading and Writing, 8, 45-59. http://dx.doi.org/10.1007/BF00423924

[50] Maeland, A.F. (1992) Handwriting and Perceptual-Motor Skills in Clumsy, Dysgraphic, and “Normal” Children. Perceptual and Motor Skills, 75, 1207-1217. http://dx.doi.org/10.2466/pms.1992.75.3f.1207

[51] Tseng, M.H. and Murray, E.A. (1994) Differences in Perceptual Motor Measures in Children with Good and Poor Handwriting. Occupational Therapy Journal of Research, 14, 19-36. http://dx.doi.org/10.1177/153944929401400102

[52] Klein, S., Guiltner, V., Sollereder, P. and Ying, C. (2011) Relationships between Fine-Motor, Visual-Motor, and Visual Perception Scores and Handwriting Legibility and Speed. Physical and Occupational Therapy in Pediatrics, 31, 103-114. http://dx.doi.org/10.3109/01942638.2010.541753

[53] Karlsdottir, R. and Stefansson, T. (2002) Problems in Developing Functional Handwriting. Perceptual and Motor Skills, 94, 623-662. http://dx.doi.org/10.2466/pms.2002.94.2.623 